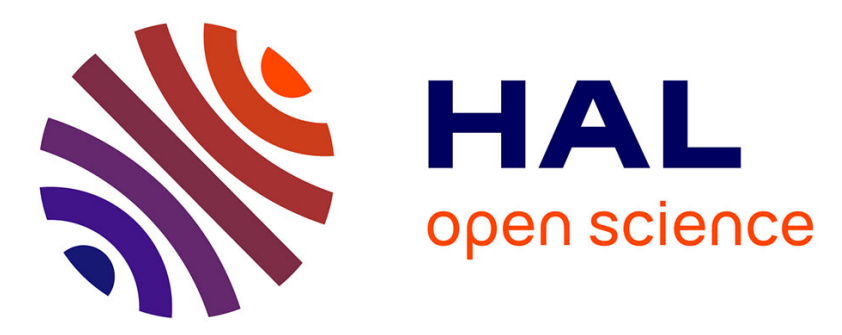

\title{
Post-Kyoto CO2 emission reduction : the soft landing scenario analysed with POLES and other world models
}

Peter Russ, Patrick Criqui

\section{To cite this version:}

Peter Russ, Patrick Criqui. Post-Kyoto CO2 emission reduction: the soft landing scenario analysed with POLES and other world models. Energy Policy, 2007, 35 (2), pp.786-796. halshs-00078489

\section{HAL Id: halshs-00078489 \\ https://shs.hal.science/halshs-00078489}

Submitted on 6 Jun 2006

HAL is a multi-disciplinary open access archive for the deposit and dissemination of scientific research documents, whether they are published or not. The documents may come from teaching and research institutions in France or abroad, or from public or private research centers.
L'archive ouverte pluridisciplinaire HAL, est destinée au dépôt et à la diffusion de documents scientifiques de niveau recherche, publiés ou non, émanant des établissements d'enseignement et de recherche français ou étrangers, des laboratoires publics ou privés. 


\section{Laboratoire d'Economie de la Production et}

de I'Intégration Internationale

Département Energie et Politiques de

l'Environnement (EPE)

FRE 2664 CNRS-UPMF

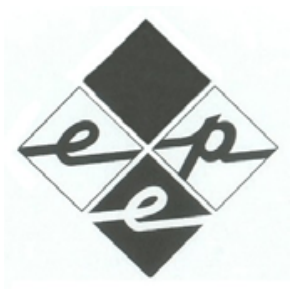

Post-Kyoto $\mathrm{CO}_{2}$ emission reduction : the soft landing scenario analysed with POLES and other world models

Article à paraître dans Energy Policy

Peter Russ

Patrick Criqui

Mai 2006 



\title{
Post-Kyoto $\mathrm{CO}_{2}$ emission reduction: the soft landing scenario analysed with POLES and other world models
}

\author{
Peter Russ ${ }^{1}$, Patrick Criqui ${ }^{2}$,
}

\begin{abstract}
Long-term outlooks are key tools for policy design in the energy sector. These outlooks should also include scenarios considering active policies that address the challenge of climate change. Consequently such a $\mathrm{CO}_{2}$ emission reduction scenario was analysed as a case study within the ACROPOLIS project.

This paper presents a method to derive regional emission targets that correspond to an emission trajectory that stabilises carbon dioxide emissions by 2030, within a concentration target set at 550 ppmv. In a next step, the impact of emission reduction on the structure of the future energy system is briefly analysed using the POLES world energy model. Finally, some key indicators are compared with the results from other world energy models used in the ACROPOLIS project to analyse the same emission reduction scenario. While the emission reduction compared to the baseline is significant, the resulting necessary adaptations in terms of energy and carbon efficiencies lie within the ranges observed in the past. It is demonstrated that the defined "soft landing" emission reduction scenario would under the assumption of emission trading produce permit prices that are not extremely high. Though forecasted effect of $\mathrm{CO}_{2}$ emission reduction on the energy system is quite different across models, the marginal reduction costs broadly coincide across the participating models. This especially is true when taking into account the different reduction efforts caused by different levels of emissions in the baseline.
\end{abstract}

Keywords: Post-Kyoto targets, model comparison, energy outlook

Introduction

The risks associated with global climate change weigh heavily on the future of the international community. It is a widely accepted fact that the future energy system will be considerably influenced by the climate change problem. Nevertheless, until recently energy outlooks did not even consider the impact of greenhouse gas reduction policies on the energy system. Because of the policy relevance of such analyses within the ACROPOLIS project ${ }^{3}$ a case study on the impact of an active policy to reduce $\mathrm{CO}_{2}$ emission was included. In this paper, the results from this analysis looking at the differences between a "business-as-usual" outlook for the energy system and a case that

\footnotetext{
${ }^{1}$ IPTS, Joint Research Centre, European Commission, Sevilla.

${ }^{2}$ Institute of Energy Policy and Economics, CNRS/LEPII-EPE, Grenoble.

${ }^{3}$ See introductory article in same Special Issue
} 
takes into account a global effort to reduce $\mathrm{CO}_{2}$ emissions will be presented. To be able to carry out such analyses with a time horizon of 2030, a consistent scenario for $\mathrm{CO}_{2}$ control strategies beyond the first commitment period as defined in the Kyoto protocol is necessary. Consequently, the first part of the paper describes the "soft landing" scenario applied in this analysis to define the allocation of emission allowances for the word regions. In a second part the impacts on the energy system of emission reduction policies, as defined in the "soft landing" scenario, are shown. The results presented are based on an application of the POLES ${ }^{4}$ world energy model and focus on the power sector. Additionally a brief comparison of some key indicators with results obtained from other world energy models for the same "soft landing" scenario within the ACROPOLIS project will be given.

\section{Defining emission reduction targets for the stabilisation of world emissions in $\mathbf{2 0 3 0}$}

To assess $\mathrm{CO}_{2}$ emission reduction strategies to 2030, i.e. in a post-Kyoto time frame, it is necessary to select from existing long-term scenarios, a target emission path for the period 2010-2030. The scenario should satisfy a clearly identified GHG concentration target and a related global temperature change, and in that way represent a useful basis for the comparison of the different scenarios computed.

In this section of the paper, the reasoning and the assumptions underlying the scenario used in this study are given. The "soft landing" scenario ${ }^{5}$ applied a pragmatic approach taking into account the constraints imposed by the climate system as well as the economic and energy dynamics in each world region. The method is based to a on the approach used in Kyoto, the -differentiation of targets according to groups of countries with consideration of similar variables, while adjusting the scenario to the situation of the developing countries.

In the following, three stages for the definition of the scenario are discussed:

1. Definition of the global emission target

2. Allocation of emission permits across countries (soft landing)

3. Setting of the implementation rules (flexible mechanisms).

\section{A common target to stabilise emissions}

The latest report from the Intergovernmental Panel on Climate Change (IPCC, 2001) reviews a wide variety of possible trajectories for changes in emissions of the most important greenhouse gas. They describe carbon dioxide emissions from the burning of fossil fuels from 1990 onward, leading to the stabilisation of atmospheric concentrations by 2100 or later. The scientifically defined trajectories frequently aim at stabilising carbon dioxide concentrations at a level of 550 parts per million by volume (ppmv). Although "it does not imply an agreed-upon desirability of stabilisation” (IPCC 2001,

\footnotetext{
${ }^{4}$ See brief overview in the annex and European Commission, 1996.

5 The "soft landing" scenario or slight variations of it recently also have been used in other studies. See European Commission, 2003b, Criqui et al. 2004
} 
p.124), this target is often used in political discussions ${ }^{6}$. Consequently the scenario for allocating emission allowances is based on this stabilisation hypothesis.

Most of the trajectories for stabilizing concentrations at 550 ppmv by 2100 follow an inverted U-shaped curve for carbon dioxide emissions from fossil fuel burning. After an initial growth period, emissions peak between 2020 and 2060, then briefly stabilise before to decline afterwards to different levels at different rates. The maximum of this curve most frequently ranges between 9 and 12 Gigatons of carbon (IPCC2001, pp.130, 150). The scenario used here defines that fossil fuel carbon dioxide emissions will peak at 10 Gigatons of carbon by 2030 .

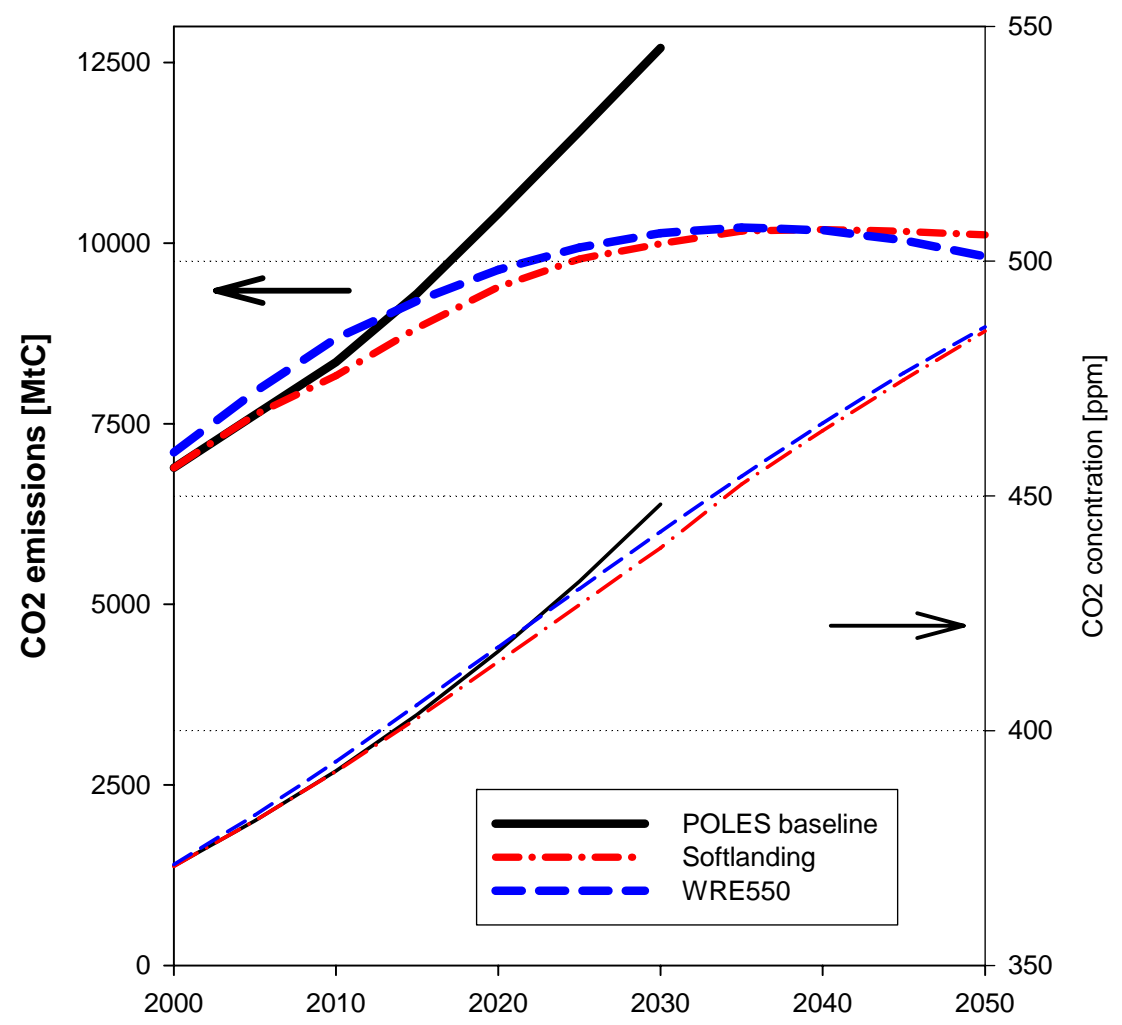

Figure 1: Changes in energy-related carbon emissions in the soft landing case compared to the POLES baseline case without emission restrictions ${ }^{7}$.

\section{Allocation of emission permits}

As a basic principle the scenario applies a differentiation between industrial and developing countries as decided in the Kyoto Protocol for the first commitment period (2008-12). This approach is employed to take into account extremely different energy and economic dynamics across countries. The international distribution rules have been selected after the analysis of the literature on international and intergenerational equity principles (see eg Banuri et al., 1996, Rose et al., 1998).

\footnotetext{
6 ".... the Council believes that global average temperatures should not exceed 2 degrees above preindustrial level and that therefore concentration levels lower than $550 \mathrm{ppm} \mathrm{CO}_{2}$ should guide global limitation and reduction efforts" (European Council , 1996)

${ }^{7}$ For sake of comparison in the figure also the well known WRE550 scenario (Wigley et al., 1996) scenario is given. The concentrations were calculated using the MAGICC climate model (Wigley et al., 2000).
} 


\section{Annex 1 countries}

For Annex 1 countries, the scenario supposes the same emission reduction rates as those in the Kyoto Protocol. The exceptions are Australia and New Zealand that are assumed to keep their emissions constant during 2010-30 and the United States. The USA are assumed to start their reduction only after 2010 from the emission level they reach in that year at a reduction rate corresponding to their commitment in the Kyoto protocol ${ }^{8}$. For the Annex 1 countries as a whole, this means that the emission reduction rate will average 6.5 percent in 2030, compared to 2010.

\section{Developing countries}

For non Annex 1 countries, based on the condition in assumption 1 that world emissions will peak and stabilise by 2030, the scenario projects that emissions will stabilise between 2015 and 2045. For these countries no "a priori” allocation principle is applied. Rather, the allocation is based on defining:

o A departure year for determining the initial situation and dynamics of these countries. This year is defined as 2010. By then, the emissions from these countries will have roughly doubled compared to 1990 levels under the business as usual scenario.

o Initial emissions growth rates, differentiated to account for regional population growth between 2000 and 2010. Gradual reductions in these rates - along with the absolute reductions imposed on Annex 1 countries - lead to overall stabilisation.

o Future target years by which emissions should stabilise. To define these, countries were grouped according to two criteria: per capita GDP and per capita carbon dioxide emissions in 2000. These criteria are not used to allocate emission allowances but only to define stabilisation horizons for each of the four resulting groups .

Group 1 in Figure 2 consists of Annex 1 countries. Although some countries (Portugal; the Czech Republic, Hungary, Poland, and the Slovak Republic (CEU4); the former Soviet Union (FSUN); and the rest of Central European countries (RCEU)) fall into groups 2 and 3 in the figure, they are Annex 1 countries and regions. Thus they are included in group 1 in the analysis for consistency with the above described assumption on the reduction rates. The resulting picture shows why the primary differentiation of the Kyoto Protocol (between Annex 1 and non Annex 1 countries) may with hindsight and with today's data be considered legitimate. Non Annex 1 countries fall into groups 2 (relatively high income and emissions), 3 (intermediate income and emissions), and 4 (low income and emissions). The basic idea behind this grouping is to define a time horizon for stabilisation: the higher are a country's income and emissions, the sooner should its emissions be stabilised. Conversely, a poor country with low per capita emissions should not be required to stabilise emissions until much later. Non Annex 1 countries will stabilise emissions according to their per capita income and per capita emissions by 2015, 2030, or by 2045 (groups 2,3, and 4, respectively).

\footnotetext{
${ }^{8}$ This assumption has important repercussions on the results, see Footnote 22.
} 


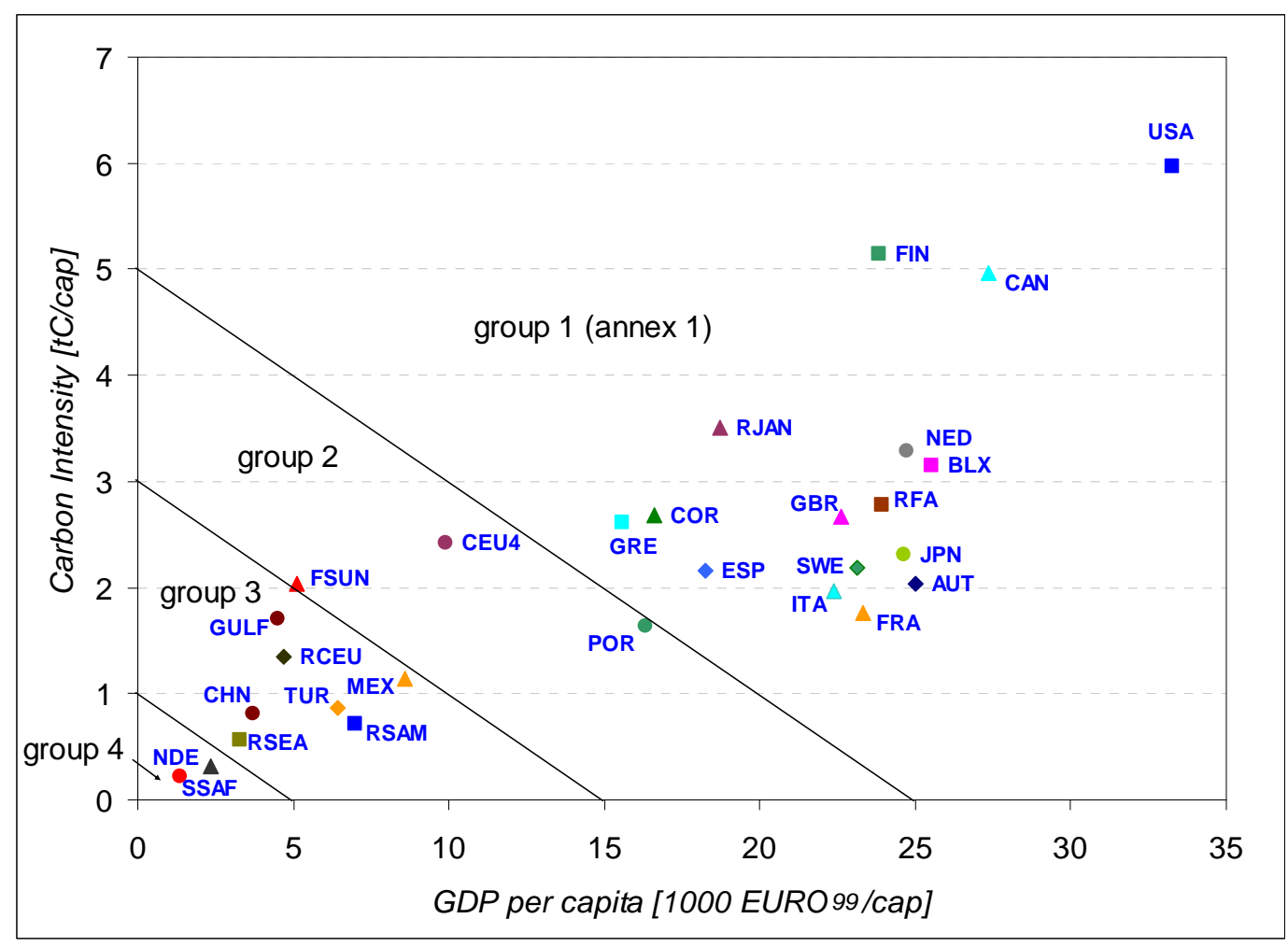

Figure 2: Differentiation of stabilisation dates for a representative set of countries ${ }^{9}$.

Having defined the target stabilisation year, the emissions allowance profiles leading from the nonbinding situation in 2010 to the country-specific stabilisation horizon are calculated based on the initial emission rate. This initial emissions growth rate in 2010 is taken as the sum of an across-the-board annual growth rate of 3 percent in per capita emissions for all developing countries and of the average annual population growth rate in each country between 2000 and $2010^{10}$. Then this initial growth rate decreases until it reaches zero in the stabilisation year $(2015,2030$, or 2045) defined for each group of developing countries. For each group, the reduction in the growth rate follows the same linear function, resulting in a smooth reduction of the emission growth rate to zero. This is the very base of the "soft landing" scenario.

\section{Summary of the allocation principles applied}

The soft landing scenario can be briefly characterised as follows:

- It aims to achieve a stabilisation of carbon emissions at 10 Gigatons by 2030 .

- It assumes that the Kyoto targets will be achieved by Annex 1 countries (excluding the USA) and reapplied for the second period (2010-30).

\footnotetext{
${ }^{9}$ Per capita GDP is expressed in constant 1999 Euros, purchasing power parity adjusted. Source: POLES model data base. The country and regional codes used are according to ISO.Exceptions: CEU4: Central Europe (Hungary, Poland, Czech Republic, Slovakia); MIEA: Middle East; FSUN: former Soviet Union; RCEU: rest Central European countries (excl. CEU4); RCAM: rest of Central America; RSAM: rest of South America (excl. Brazil); NOAF: North Africa; RSEA: rest of South-East Asia; SSAF: Sub-Saharan Africa; RSAS: rest of South Asia

${ }^{10}$ see Blanchard et al., 2000 for mathematical details on this growth rate
} 
- It proposes reducing linearly the emissions growth rates for developing countries to reach zero growth at different points in time, taking into account their per capita GDP, per capita carbon dioxide emissions, and population growth rates.

Table 1 Emission targets for the soft landing scenario compared with baseline emissions (relative to emission levels in the year 2000).

\begin{tabular}{l|c|c} 
& $\begin{array}{c}\text { Baseline Emissions 2030 } \\
\text { / Emissions 2000 }\end{array}$ & $\begin{array}{c}\text { Emission target 2030 } \\
\text { / Emissions 2000 }\end{array}$ \\
\hline EU27 & 1.19 & 0.87 \\
Other Europe & 2.01 & 1.54 \\
CIS & 1.61 & 1.45 \\
USA & 1.19 & 0.93 \\
Canada & 1.31 & 0.69 \\
Central America & 1.38 & 1.13 \\
South America & 1.85 & 1.38 \\
Middle East & 2.11 & 1.91 \\
Africa & 3.23 & 2.52 \\
China & 2.50 & 2.14 \\
India & 3.31 & 2.76 \\
Other East Asia & 3.04 & 1.86 \\
Other South Asia & 4.20 & 3.01 \\
Japan & 1.08 & 0.88 \\
Australia \& Oceania & 1.58 & 0.82 \\
& & \\
\hline World & 1.83 & 1.43
\end{tabular}

Figure 3 shows emissions under the scenario for 2000-50, differentiated by country group. The scenario achieves the overall target: combined emissions are stabilised at 10 Gigatons of carbon in 2030. In addition, the global stabilisation target is reached: emissions from Annex 1 countries decrease over the entire period, while emissions from group 2 countries stabilise in 2015, those from group 3 countries in 2030, and those from group 4 countries in 2045. Of the 10 Gigatons of carbon in 2030, 3.8 Gigatons are endowed to Annex 1 countries and 6.1 Gigatons to developing countries. 


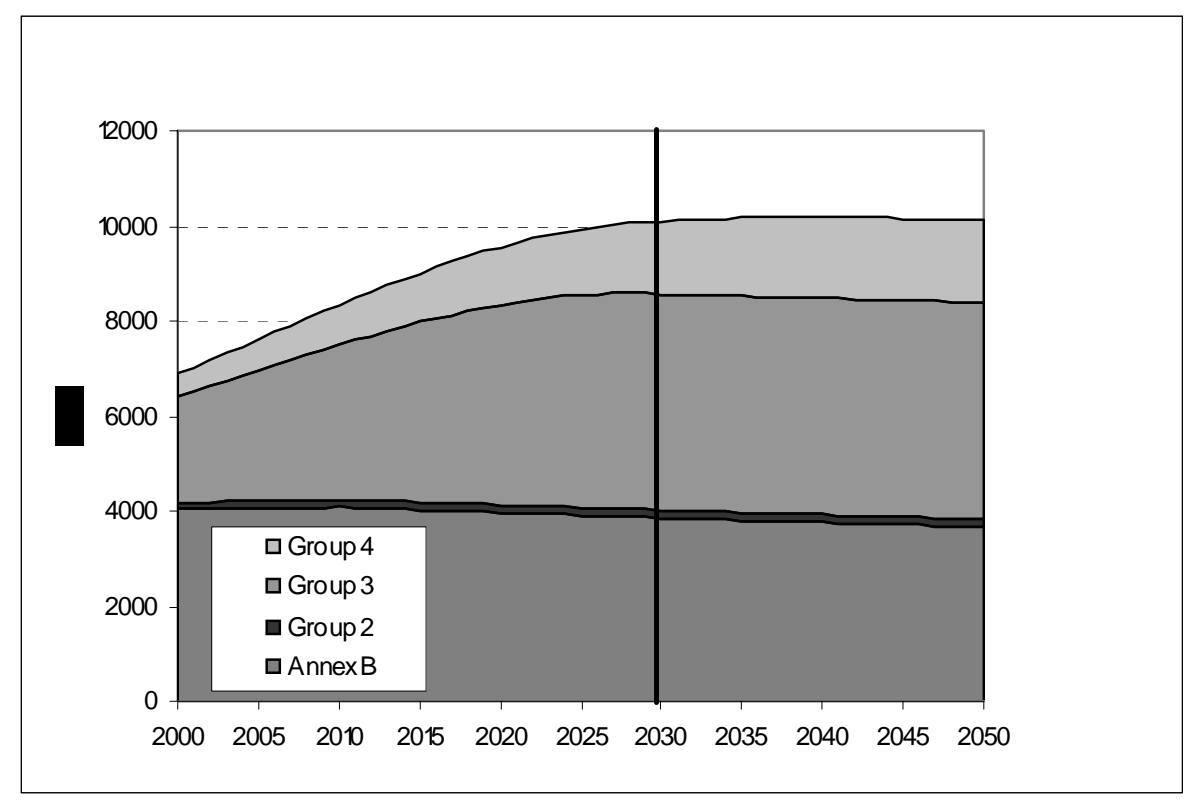

Figure 3: $\mathrm{CO}_{2}$ emission profile for the soft landing scenario.

\section{Assumptions on International Flexibility Mechanisms}

Beyond the definition of the emission reduction target for the analyses on the impact of $\mathrm{CO}_{2}$ reduction policies on the energy system, it is necessary to define the conditions under which the overall emission reduction target should be reached. As it is the case in the Kyoto protocol and its implementation in Europe, rules have to be fixed concerning emission trading mechanisms, besides the country emission permit endowments. The flexibility mechanisms allowed and the countries or sectors involved in the implementation of the emission reduction policy have to be defined.

Even if the principles of soft landing scenario do take into account the economic situation of the individual, regions it would probably imply different burdens, depending on the actual structure of the regional energy systems and it's future development as projected in the baseline. There is general agreement that flexible mechanisms as defined in the Kyoto protocol will contribute considerably to meet emission reduction target in a more efficient way ${ }^{11}$. It seems to be unlikely that future climate policy targets will be agreed upon without allowing for the use of flexible mechanisms. In this case study full international trade of emission permits has thus been assumed. Whilst this may be a hypothetical case of least cost reduction, it however provides the possibility of comparing results across models: world energy models have a limited geographical resolution (limited number of regions) and even a non-trade case implicitly assumes inter-region trade; consequently, inter-model comparisons depend on their respective breakdown into regions. For the purpose of a inter-model comparison, a full-trade case has thus been judged more convenient and has been run within the ACROPOLIS by the participating modelling teams.

The following assumptions were necessary to define the implementation of the scenario:

- Banking is not allowed, emission targets have to be met each period.

${ }^{11}$ See e.g. Criqui et al. 1999, Gusbin et al. 1999, Energy Journal, 1999, UNCTAD, 2001. 
- The USA are assumed not to ratify the Kyoto Protocol in 2010 and is not allowed to trade in the first commitment period.

- In 2010, only 50\% of the "hot air" available can be traded. This assumption is in line with models that simulate market power on the emission permit supply side $^{12}$.

- Measures based on the Clean Development Mechanism (CDM) are not considered.

- After 2010, all regions participate in trading as long as they have binding emissions reduction obligations (no 'hot air" trading partners).

\section{Assessment in terms of achievability, equity and efficiency}

In order to be policy relevant, a scenario not only has to be based on scientific grounds (here: $\mathrm{CO}_{2}$ concentration stabilisation targets), but acceptability and feasibility aspects have also to be considered. The emission reduction targets should be realistic and achievable. The allocation patterns have to be consistent with some basic criteria of equity and fairness. And, not the least, efficiency, i.e. the possibility to reach the emission target at least cost, is important.

Abundant literature exists on emission trading and on the corresponding advantages in terms of global efficiency to reach emission reduction targets ${ }^{13}$. For the analysis which is presented here, emission trading has been assumed to be a prerequisite for an active policy to reduce greenhouse gas emissions. A detailed comparison between a trade case and a non-trade case, therefore, is omitted here. The definition of the scenario including full emission trading implies that the emission target is met in an efficient way.

A politically acceptable relevant scenario has to fulfil some basic requirements in terms of equity and fairness. Gauging the equity of a distribution depends on the principle of justice used to define equity (Blanchard et al., 2000). One way is to consider the changes in the distribution of per capita emissions over the period. Figure 4 shows Lorenz curves and Gini coefficients for world carbon dioxide emissions in 1990, 2010, and $2030^{14}$.The 1990 curve represents real carbon dioxide emissions, or de facto allowances for that year. The 2010 curve shows the de jure distribution of emission allowances as called for in the Kyoto Protocol. The 2030 curve is based on the allocation of allowances under the soft landing scenario. When a Lorenz curve is a straight line, the distribution is considered perfectly egalitarian. In the allocation of allowances such a distribution would reflect universally equal per capita emissions. Thus Figure 4 shows that the situation in 1990 was the most unequal, the situation in 2010 will be less unequal, and the hypothetical situation in 2030 even less unequal. These observations are confirmed by the Gini coefficients, which drop from 0.52 in

\footnotetext{
${ }^{12}$ Böhringer, 2001 for instance finds that at a level of 40\% revenues of the sellers (mainly Russia) are maximised. This as well as the $50 \%$ assumption in the softalnding scenario applies only for the case that the USA is not participating in emission trading in the first commitment period..

${ }^{13}$ see references in footnote 11 . Blanchard et al. 2000 contains an analysis on the advantages of emission trading for a variant of the soft landing scenario.

${ }^{14}$ The Lorenz curve and the Gini coefficient were created to measure inequality in a population's income distribution. They can also be used to measure equity in the distribution of other assets, such as emission allowances
} 
1990 to 0.41 in 2010 and 0.35 in $2030^{15}$. Thus the soft landing scenario would reduce inequalities among countries by moving toward more equal per capita emission allowances.

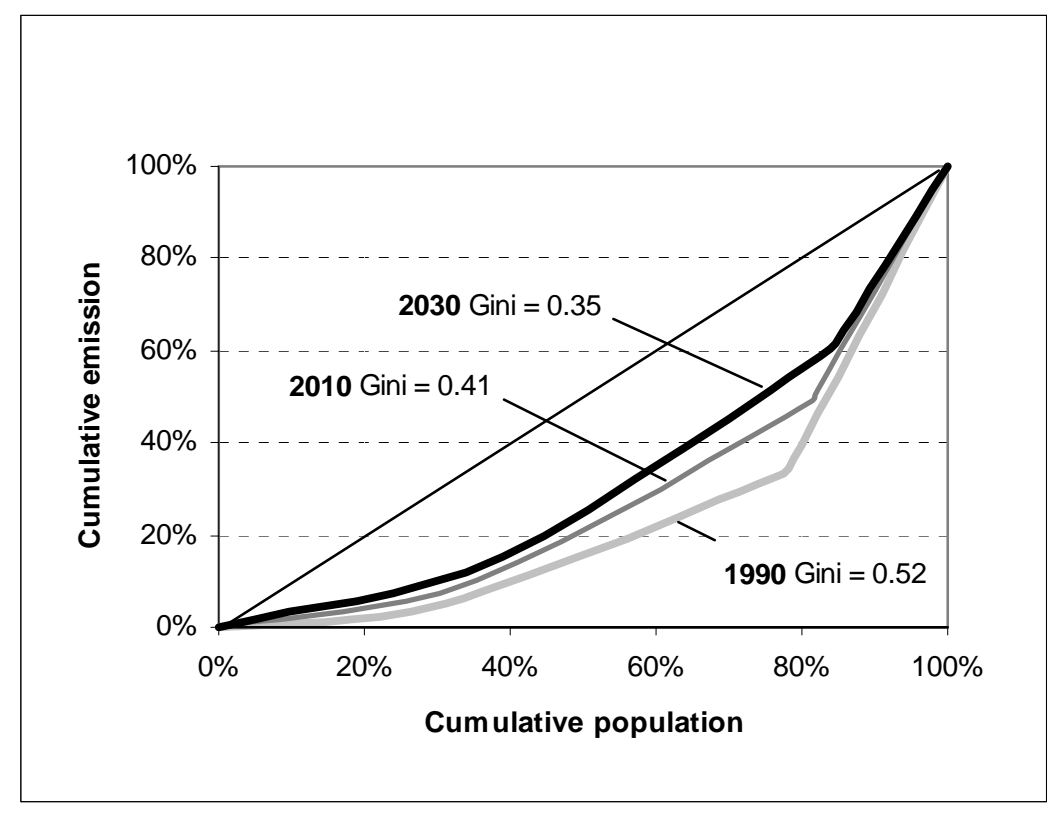

Figure 4: Lorentz curve and Gini coefficients for World emission endowments

To design a relevant scenario for policy conclusions besides scientific considerations and equity issues, the question of achievability should also be considered. Here this issue will be only briefly addressed by comparing the regional emission reduction targets of the soft landing scenario with historic developments. This simple approach assumes that if the targets lie within the range of past developments, they may be achievable simply because meeting the target only means changes that are comparable to past developments. Figure 5 gives a comparison of historic annual change rates of $\mathrm{CO}_{2}$ emissions over annual GDP growth (light grey dots) with the emission targets of the soft landing scenario (black dots). Even if no clear relation between GDP growth and $\mathrm{CO}_{2}$ emission change can be derived based on the data, it can be stated that the changes ask for in the soft landing scenario lie in the range of historic developments and hence seem to be achievable.

\footnotetext{
${ }^{15}$ A Gini coefficient of 0 indicates a perfectly equal distribution; a coefficient of 1 indicates a fully unequal distribution.
} 


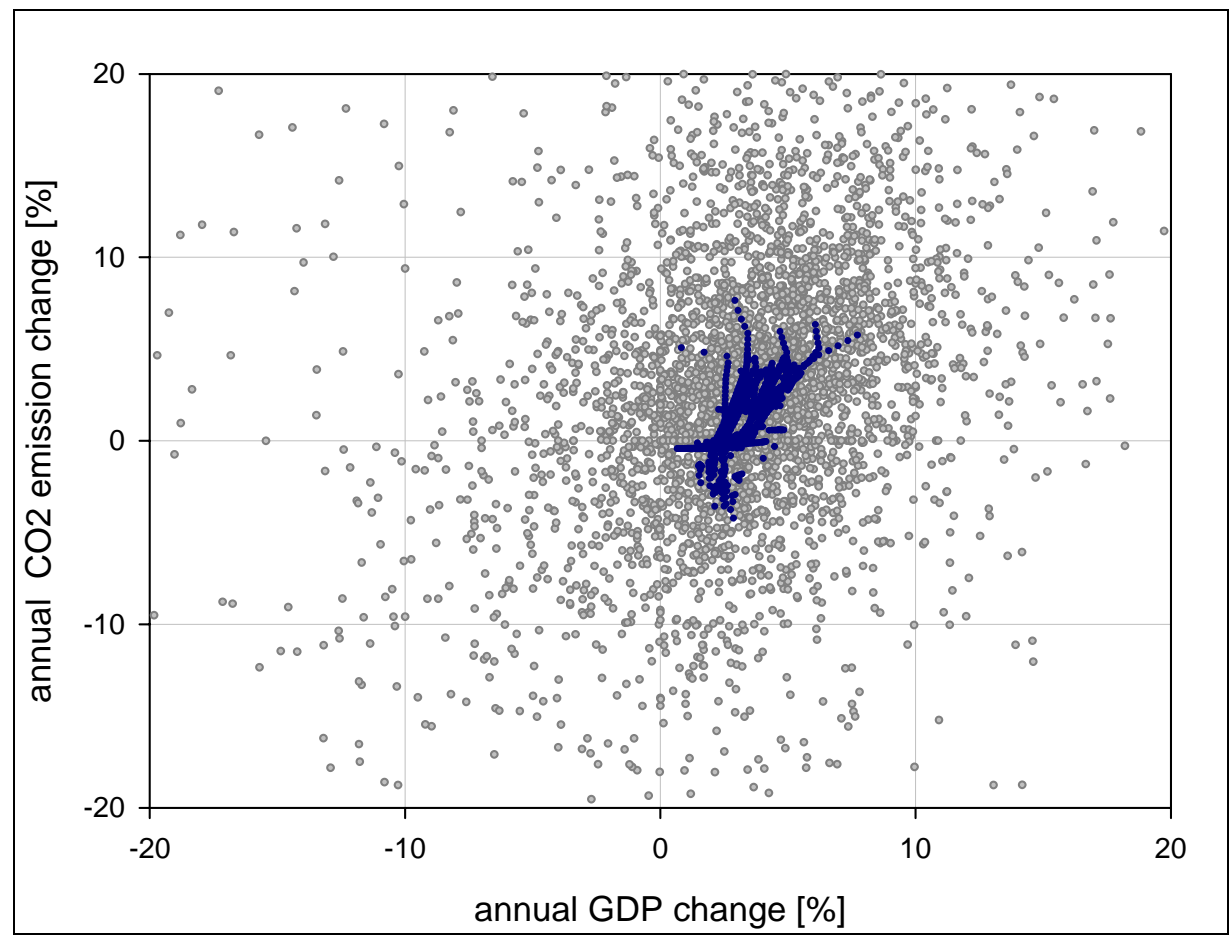

Figure 5: Annual GDP change versus annual $\mathrm{CO}_{2}$ emissions for the world in the last 30 years (grey) ${ }^{16}$ and targets of the ACROPOLIS soft landing scenario (black).

\section{The reference and soft landing scenarios: Results with the POLES model}

In this section, the main results of a detailed analysis of the soft landing scenario as defined above with the POLES model ${ }^{17}$ are presented. To assess the impact of the emission reduction scenario on the energy system, the soft landing scenario is compared with a baseline case with no action to reduce emissions. Some results concerning emission trading are discussed and the emission permit price in the assumed emission permit market is given.

\section{The reference case}

This section summarizes the impact on the energy system of the $\mathrm{CO}_{2}$ reduction, as imposed by the soft landing scenario. As a reference scenario against which these changes are compared, the POLES baseline scenario provides a description of the future world energy system, under a continuation of the on-going trends and structural changes in the world economy. This baseline is developed in a "business and technical change as usual” context, while no policies to reduce greenhouse gas emissions are included. The scenario serves as a benchmark for the assessment of alternatives, particularly with

\footnotetext{
${ }^{16}$ Source: ENERDATA, 2004. For this analysis world country data from 1970 to 2001 with the exception of small islands eg Tonga, Samoa,etc have been used. Only countries having a per capita GDP of 1500 \$ or more were considered.

${ }^{17}$ See annex and European Commission, 1996.
} 
respect to resources, technologies and environmental policy. It is $\operatorname{similar}^{18}$ to the scenario described in great detail in European Commission, 2003a. The most important features of this scenario (see Table 2) are the following:

World energy demand is projected to increase at about 1.8\%/year between 2000 and 2030. The impact of economic and population growth is moderated by a decrease in the energy intensity of $1.2 \%$ year, due to the combined effects of structural changes in the economy, of technological progress and of energy price increases. Industrialised countries experience a slowdown in the growth of their energy demand to a level of e.g. $0.4 \% / y e a r$ in the EU. Conversely, the energy demand of developing countries growths rapidly. In 2030, more than half of the world energy demand is expected to come from developing countries, compared to $40 \%$ today.

The world energy system continues to be dominated by fossil fuels with almost $85 \%$ of total energy supply in 2030. Oil remains the main source of energy (33\%) followed by coal (27\%). Almost two-thirds of the increase in coal supply between 2000 and 2030 comes from Asia. Natural gas is projected to represent one quarter of world energy supply by 2030; power generation provides the bulk of the increase. In the EU, natural gas is expected to be the second largest energy source, behind oil but ahead of coal and lignite. Nuclear and renewable energies would altogether represent slightly less than $20 \%$ of EU energy supply. Coal remains the major fuel for power generation. The overall increase of coal is pushed by the increasing demand in Asia.

Given the continued dominance of fossil fuels, world $\mathrm{CO}_{2}$ emissions are expected to increase more rapidly than energy consumption (2.1\%/year on average). In 2030, world $\mathrm{CO}_{2}$ emissions are more than twice the level of 1990. In the EU, $\mathrm{CO}_{2}$ emissions are projected to increase by $18 \%$ in 2030 compared to the 1990 level; in the USA the increase is around 50\%. While the emissions from developing countries represented only $30 \%$ of the total in 1990 , these countries are responsible for more than half the world $\mathrm{CO}_{2}$ emissions in 2030.

\section{Impact of the soft landing scenario on the world energy system}

In the following a brief summary of the results of the soft landing scenario is given (see also Table 2). Here the baseline scenario without $\mathrm{CO}_{2}$ emission reduction targets is taken as a reference. If not mentioned otherwise, the results discussed below refer to changes as compared to the baseline scenario in the year 2030.

Table 2: Baseline and soft landing scenario

\begin{tabular}{|l|c|c|c|c|c|c|c|}
\hline & & & $\begin{array}{c}\text { Baselin } \\
\text { e }\end{array}$ & & $\begin{array}{c}\text { soft } \\
\text { landing }\end{array}$ & & change \\
\hline Overall Indicators & & 2000 & 2010 & 2030 & 2010 & 2030 & 2030 \\
\hline $\begin{array}{l}\text { Gross inland consumption } \\
\text { per capita }\end{array}$ & GJ/cap & 70.0 & 73.9 & 88.9 & 73.4 & 78.0 & $-12 \%$ \\
\hline $\begin{array}{l}\text { Gross inland consumption / } \\
\text { GDP }\end{array}$ & GJ/kEUR & 10.9 & 9.2 & 7.5 & 9.1 & 6.8 & $-10 \%$ \\
\hline
\end{tabular}

\footnotetext{
${ }^{18}$ The original scenario was modified according to the common basic assumptions definined for the ACROPOLIS project (see overview article same Special Issue).
} 


\begin{tabular}{|l|c|c|c|c|c|c|c|}
\cline { 2 - 8 } $\begin{array}{l}\text { Electricity from renewables } \\
\text { and hydro }\end{array}$ & $\%$ & 22.0 & 22.4 & 17.3 & 22.7 & 23.7 & $37 \%$ \\
\hline CO2 emissions per capita & $\mathrm{tCO}_{2} / \mathrm{cap}$ & 4.1 & 4.4 & 5.7 & 4.4 & 4.5 & $-21 \%$ \\
\hline Gross inland consumption & EJ & $\mathbf{4 4 9}$ & $\mathbf{5 3 6}$ & $\mathbf{7 7 0}$ & $\mathbf{5 3 3}$ & $\mathbf{6 9 4}$ & $\mathbf{- 1 0 \%}$ \\
\hline Natural gas & EJ & 93 & 118 & 188 & 119 & 186 & $-1 \%$ \\
\hline Oil & EJ & 152 & 182 & 250 & 181 & 228 & $-9 \%$ \\
\hline Coal & EJ & 105 & 126 & 208 & 123 & 119 & $-43 \%$ \\
\hline Nuclear & EJ & 28 & 34 & 35 & 34 & 53 & $53 \%$ \\
\hline Other & EJ & 71 & 77 & 89 & 77 & 108 & $21 \%$ \\
\hline Electricity generation & TWh & $\mathbf{1 3 7 2 0}$ & $\mathbf{1 8 2 1 9}$ & $\mathbf{3 4 4 7 0}$ & $\mathbf{1 8 1 3 2}$ & $\mathbf{3 1 5 9 0}$ & $\mathbf{- 8 \%}$ \\
\hline Natural gas & TWh & 1380 & 2966 & 8625 & 3174 & 10027 & $16 \%$ \\
\hline Oil & TWh & 1034 & 916 & 1088 & 932 & 1077 & $-1 \%$ \\
\hline Coal & TWh & 5662 & 7095 & 15579 & 6766 & 8056 & $-48 \%$ \\
\hline Nuclear & TWh & 2627 & 3155 & 3227 & 3155 & 4933 & $53 \%$ \\
\hline Hydro & TWh & 2776 & 3382 & 4558 & 3384 & 4735 & $4 \%$ \\
\hline Renewables & TWh & 241 & 704 & 1393 & 722 & 2763 & $98 \%$ \\
\hline CO $\mathbf{2}_{\mathbf{2}}$ Emissions & GtCO & $\mathbf{2 4 . 9 5 0}$ & $\mathbf{3 0 . 2 5 0}$ & $\mathbf{4 6 . 5 7 0}$ & $\mathbf{2 9 . 9 4 0}$ & $\mathbf{3 6 . 6 3 0}$ & $\mathbf{- 2 1 \%}$ \\
\hline
\end{tabular}

The total energy consumption in the soft landing case is reduced by $10 \%$ compared with the reference. Behind this relatively moderate change are significant adjustments in the demand for fuels. While gas stays virtually at the same level $(-1 \%)$, the contribution of nuclear energy increases by $53 \%$ and that of renewables by $21 \%{ }^{19}$. Oil use decreases by only $9 \%$ because the bulk of energy demand for transport in 2030 still we be covered by oil. Coal the fossil fuel with the highest carbon dioxide emission factor suffers a decrease of $43 \%{ }^{20}$.

The power sector contributes with $30 \%$ to the global $\mathrm{CO}_{2}$ emissions, as compared to $34 \%$ in the baseline. The total electricity generation is reduced a little bit less than the total energy demand (-8\%). Carbon-free electricity, coming from nuclear and renewables indeed partly replaces fossil fuel use in the demand sectors.

In relative terms, renewables are increasing most (98\%) followed by nuclear energy $53 \%$. In the power sector gas is increasing its contribution, of $16 \%$ compared to the reference. In 20307.3 times more electricity would be produced using gas as compared with 2000. Coal again is loosing share and compared to the reference the amount of electricity produced using coal as a fuel is reduced approximately by half (-48\%). Gas in this case it taking over as the main fuel for power (32\%), while coal nevertheless still contributes to $25.5 \%$ of the world's electricity.

Looking in more detail at the power sector, a marked shift in the electricity generation technologies ${ }^{21}$ can be noted. While modern gas combined-cycle power plants, nuclear plants and renewable each add roughly 1500 TWh the conventional coal power plants

\footnotetext{
${ }^{19}$ It has to be underlined here that the relative increase in renewables is significantly diminished by the taking into account of stagnating traditional fuels, while new renewables experience much higher relative growth.

${ }^{20}$ It should be noted that in this study $\mathrm{CO}_{2}$ capture and sequestration has not been considered. This option will be investigated in detail in the follow-up projects CASCADE-MINTS and WETO H2.

${ }^{21}$ On the importance on the available power generation technologies on the marginal abatement cost see Russ (2004).
} 


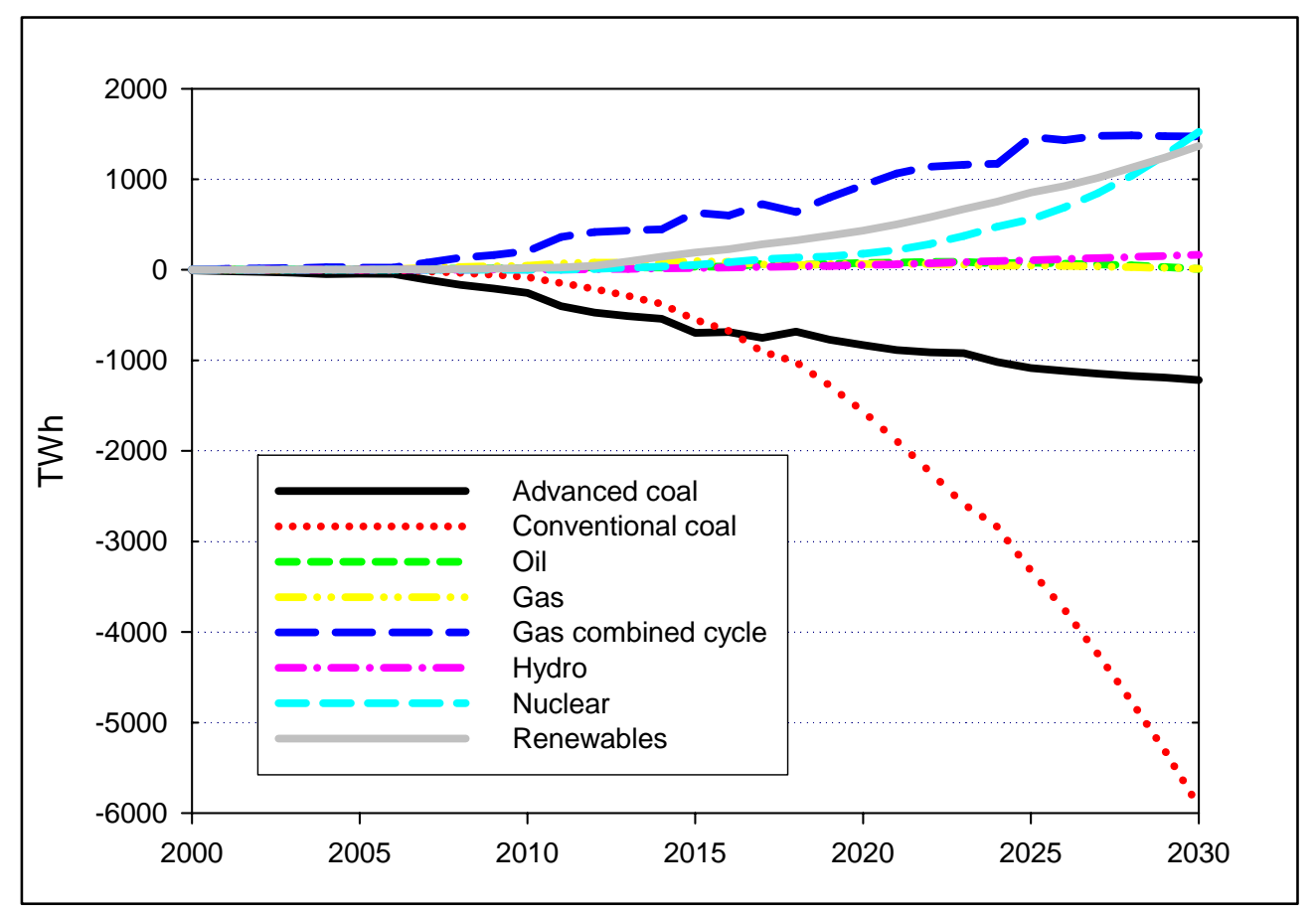

Figure 6: Impact of the soft landing scenario on power generating technologies, compared to baseline

loose around 6000 TWh. The reduced total demand for electricity (-2600 TWh) is mainly affecting the coal technologies.

\section{International Emission Permit Trade}

Full International trade has been assumed. Whilst this represents a somewhat hypothetical case of the economist ideal of least cost reduction through the equalisation of marginal abatement cost, it also provides a sound basis for comparing results across models. Necessarily world energy models have a limited geographical resolution (number of regions identified). Therefore, even a non-trade case implicitly assumes inter-region trades and consequently comparisons between models depend on their respective breakdown into regions. For the purpose of the inter-model comparison within the ACROPOLIS project a full-trade case has therefore been run by all participating modelling teams.

Table 3: Ratio of domestic reduction and trade volume

\begin{tabular}{l|c|c} 
& $\begin{array}{c}\text { Domestic reduction/ } \\
\text { target reduction }\end{array}$ & $\begin{array}{c}\text { Amount traded } \\
{[\mathrm{Mt}]}\end{array}$ \\
\hline EU27 & 0.669 & 118 \\
Other Europe & 0.698 & 17 \\
CIS & 1.848 & -82 \\
USA & 1.104 & -45 \\
Canada & 0.510 & 45 \\
Central America & 0.791 & 11 \\
South America & 0.579 & 64 \\
Middle East & 0.136 & 50 \\
Africa & 0.860 & 26 \\
China & 2.088 & -416
\end{tabular}




\begin{tabular}{l|c|c} 
India & 1.460 & -82 \\
Other East Asia & 0.515 & 257 \\
Other South Asia & 0.593 & 18 \\
Japan & 0.528 & 28 \\
Australia \& Oceania & 0.529 & 39
\end{tabular}

Table 3 shows the domestic abatement rate for different world regions. This ratio describes how much of the emission reduction from the baseline that is required in the soft landing case is achieved domestically. Values higher then unity mean more reductions than required and therefore sales of emission permits on the emission permit market. The analysis shows that most of the industrialised regions will cover one third (EU27) up to almost half (Canada) of their emission reduction obligations by buying emission permits. The exception here are the USA, which in this case even sell some emission permits. This is because they do not follow the first commitment period target of the Kyoto Protocol and because the scenario allows for an increase in emissions until 2010, only asking for reductions afterwards, from a high value that leaves this country with relatively cheap options to reduce $\mathrm{CO}_{2}$ emissions ${ }^{22}$.

The bulk of emission permits sold originates from China, the former Soviet Union and India. In the baseline, these countries cover a significant part of their rapidly growing energy demand by new coal power plants, while in the soft landing case, part of these new plants are changed into gas plants. The necessary condition for this development is of course the availability of gas in China and India.

Table 4: POLES Carbon Values

\begin{tabular}{cccc}
\hline YEAR & 2010 & 2020 & 2030 \\
\hline Carbon Value [€ $\left.\epsilon_{95} / \mathrm{tC}\right]$ & 16.5 & 79.0 & 129.3 \\
\hline
\end{tabular}

Table 4 contains the POLES model Carbon values for the year 2010-2030. The carbon values follows a regularly increasing path over the period, which seems consistent with the set assumptions used for the design of the soft landing scenario.

\section{The soft landing scenario across different world models}

The ACROPOLIS project has been designed as a model comparison study aiming at deriving at robust policy options for climate policy. After harmonising the basic model assumptions, the same set of scenarios was analysed by a number of different models. The participating world models included general equilibrium models, optimization models, simulation models and integrated assessment models ${ }^{23}$. The soft landing scenario described above was one of the case studies considered in the project.

\footnotetext{
${ }^{22}$ This result is inconsistent with the equity principles underlying the soft landing scenario. It is a logical consequence of the assumptions on the USA participation in $\mathrm{CO}_{2}$ reduction efforts based on the USA announcement not to ratify the Kyoto protocol.

${ }^{23}$ For an overview please see >summary article, same Special Issue. For a more detailed analysis also regional models were applied and the impact on the economy as a whole was studied (see Mantzos et. al. in this Special Issue).
} 
In this section the results for the different world models running the soft landing scenario will be briefly presented. Considering the complexity of the world models used and the differences in methodology and characterisations of the energy system in the case study, the comparison will be restricted to global aggregated indicators only: the Carbon value (emission permit price), as an indicator for marginal abatement costs, and energy and carbon intensities.

\section{Reduction costs}

Even after the harmonization of basic assumptions the baselines as obtained from the different models exhibit considerable differences.

Figure 7 compares the baselines of the participating world models with the emission trajectory as defined in the soft landing scenario. Embedded assumptions on the development and availability of technologies (e.g. renewables) lead to different patterns of energy use and supply in the different baselines. Using the same emission reduction target, this means that for the different models the effort to reduce emission varies significantly. This is reflected by the permit prices calculated by the different models (Table 5).

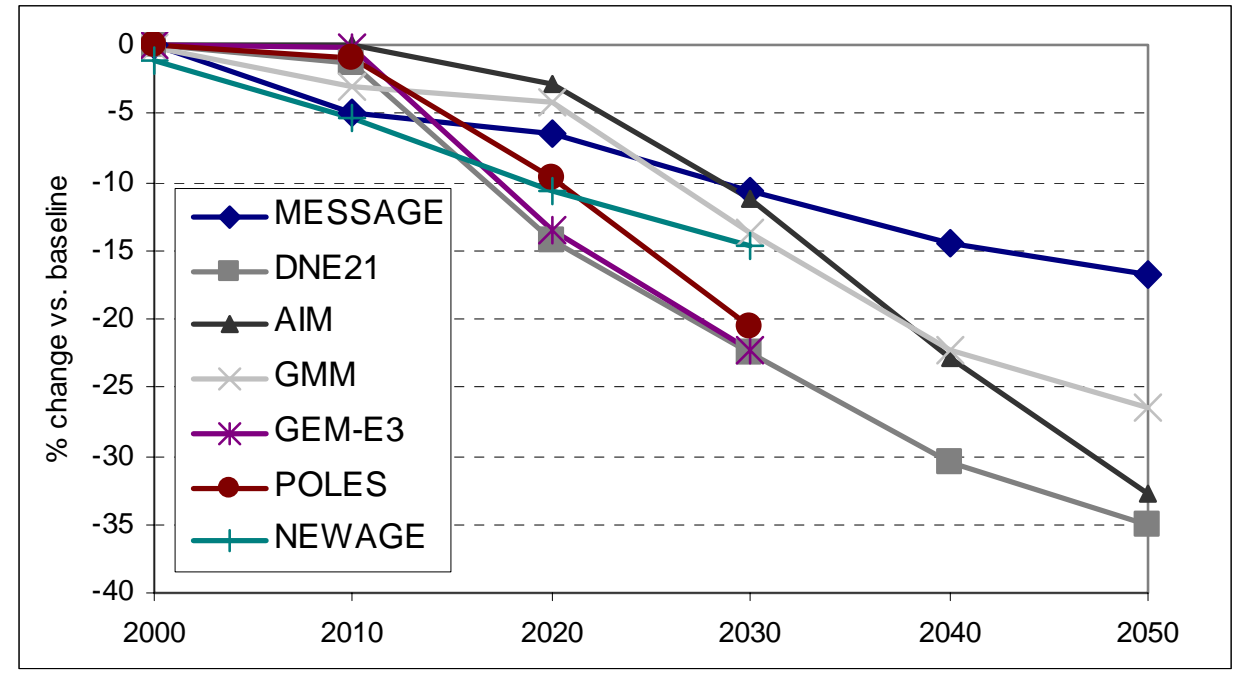

Figure 7: Relative reduction of the soft landing vs. the different model baselines

Table 5: Carbon Emission permit prices for the soft landing scenario derived by different world energy models.

\begin{tabular}{lccccc}
\hline [ $\left.\epsilon_{95} / \mathrm{tC}\right]$ & $\mathbf{2 0 1 0}$ & $\mathbf{2 0 2 0}$ & $\mathbf{2 0 3 0}$ & $\mathbf{2 0 4 0}$ & $\mathbf{2 0 5 0}$ \\
\hline MESSAGE & 142.0 & 53.5 & 39.8 & 41.7 & 40.5 \\
DNE21 & 0 & 99.8 & 135.0 & 169.8 & 222.4 \\
GMM & 45.2 & 58.8 & 35.5 & 70.2 & 75.2 \\
AIM & 40.5 & 62.2 & 106.1 & 142.5 & 117.2 \\
POLES & 16.5 & 79.0 & 129.3 & & \\
NEWAGE & 32.1 & 61.7 & 80.1 & & \\
\hline
\end{tabular}

Plotting the permit prices against the emission reduction required in the soft landing scenario (see Figure 8) shows that the differences can be explained to a considerable 


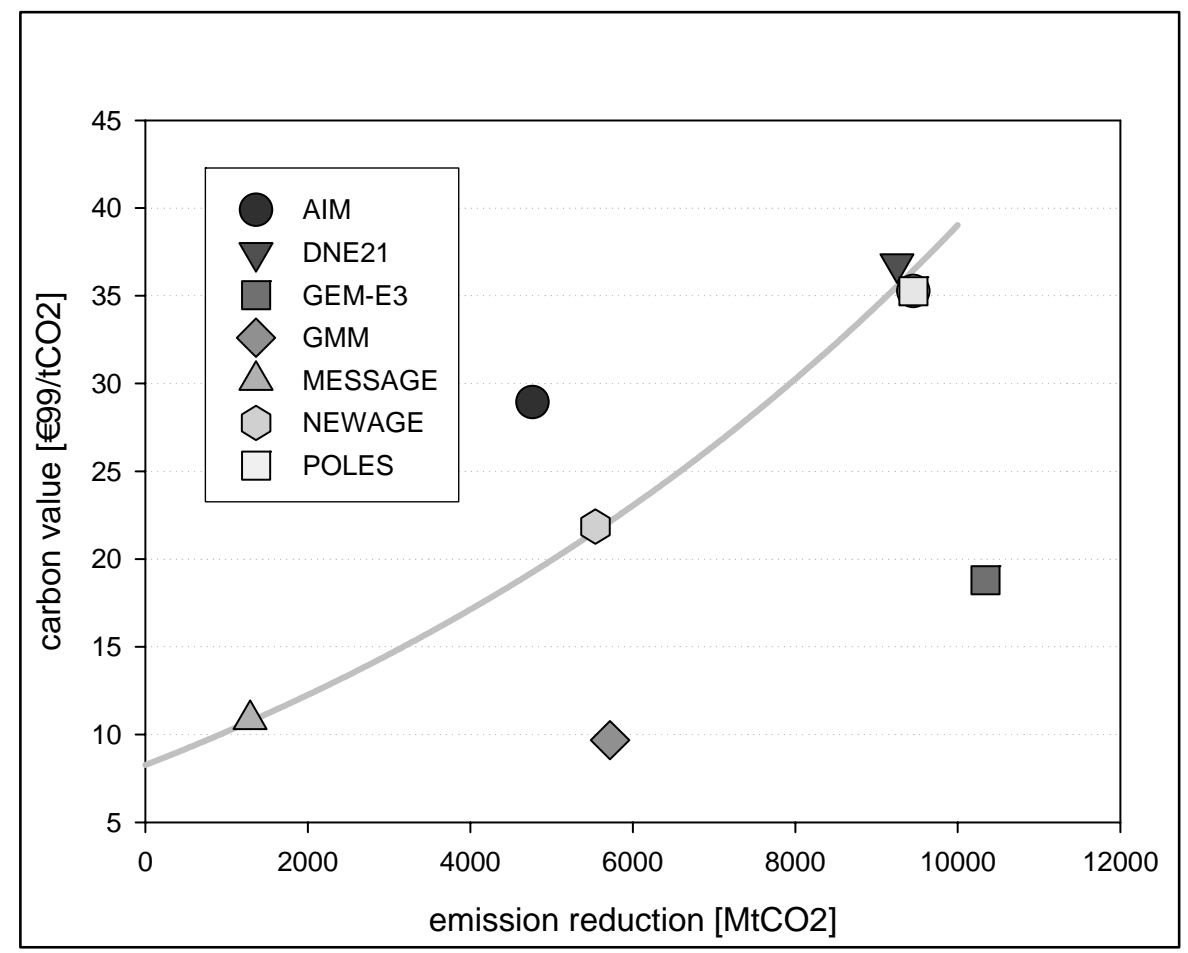

extent by the differences in emission reduction. This result underlines the importance of the baseline when discussing reduction costs.

Figure 8: Emission permit prices for the soft landing case for different models in the year 2030.

Also the different nature of models can explain part of the differences in permit prices. The general equilibrium models tend to produce lower permit prices, since, conversely to energy models, they allow adjustments in the whole economy (level and structure of activity) (GEM-E3). Optimisation models (GMM, MESSAGE) with perfect foresight should have smoother trajectories, without steep increases for permit prices as compared to models that operate in a "myopic anticipation" simulation framework (POLES).

\section{How to reduce: Energy and carbon intensities}

To assess how, according to the different models, the emission reductions are achieved, energy and carbon intensities are used as indicators. The reduction in the energy intensity is similar for four of the five models, and generally it is quite modest, about 5 percent lower than in the baseline by 2050. This is indeed largely due to the energy intensity improvements already assumed in the baseline.

The reduction in the carbon intensity shows larger differences across the models, although three exhibit similar characteristics up to 2030, with a reduction of 10 to 15 percent compared to the baseline (Figure 9). Thus the emission reduction through lower carbon intensities seems to be higher than those achieved by lower energy intensity. It can be seen that most of the models meet the emission reduction target on a trajectory that more or less extrapolates the historic developments. Together with the comparison made earlier on the historic development of GDP versus $\mathrm{CO}_{2}$ emission (Figure 5) this gives an indication that the emission target set by the soft landing scenario does not deviate considerably from historic trends. 


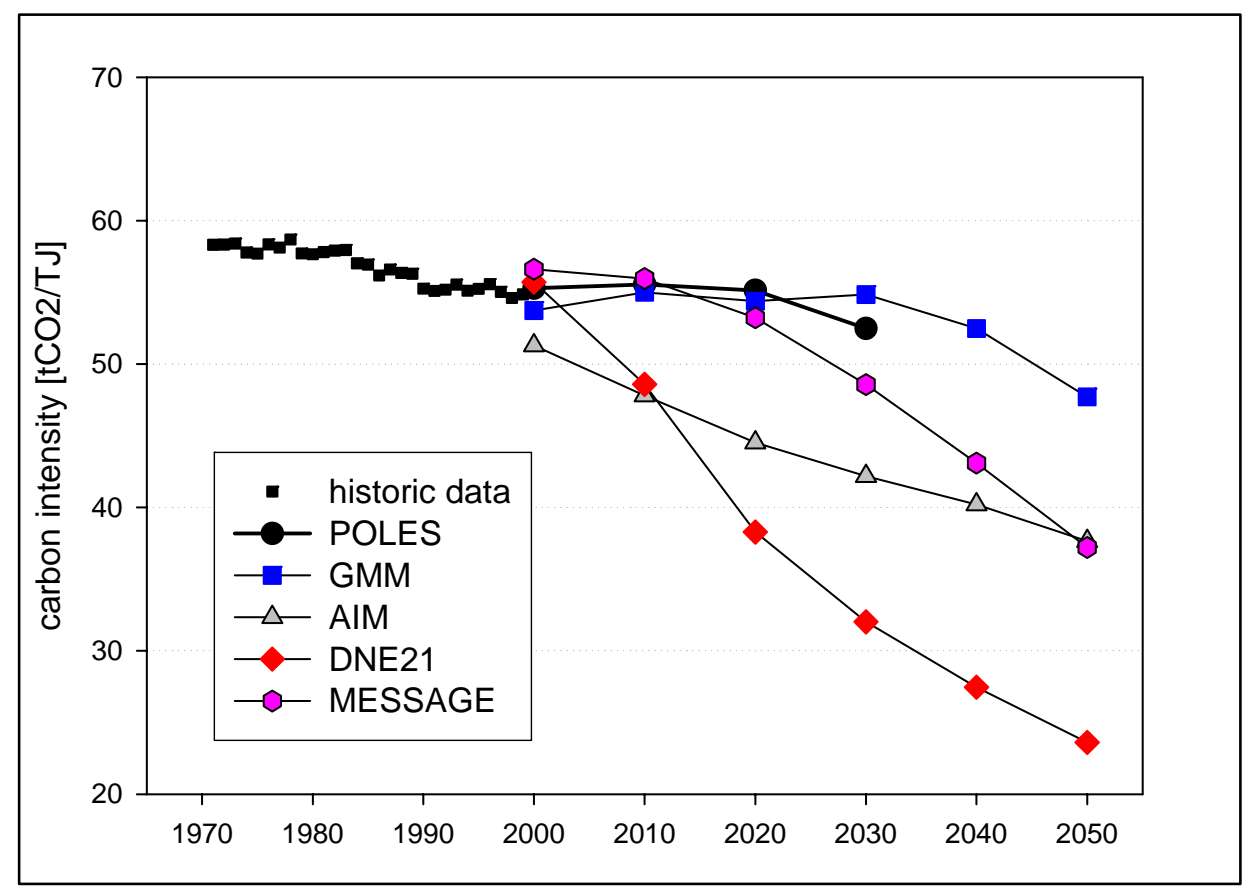

Figure 9: Carbon intensity of energy in the baseline

Figure 10 allows to compare at a glance how the different models achieve the emission reduction defined in the soft landing case. The projection as to how the energy system would be changed to meet emission reduction targets vary to a considerable extent. While MESSAGE meets the target by reducing carbon intensity ${ }^{24}$ only, AIM is mainly reducing the energy intensity to meet the target. The other models show that both energy and carbon intensities may be reduced, and the POLES model presents a particularly balanced profile. The changes in intensities reflect the fact that the share of the different fuel in total world energy supply differs considerably across the models. While one model that achieves emission reduction mainly through increased energy intensity maintains coal as the main energy source, the others reduce emission by higher shares of renewables, gas and nuclear (up to 15\%).

\footnotetext{
24 The MESSAGE model version used for this case study does not have an elastic demand and therefore the energy intensity cannot be changed as result of the carbon constraint.
} 


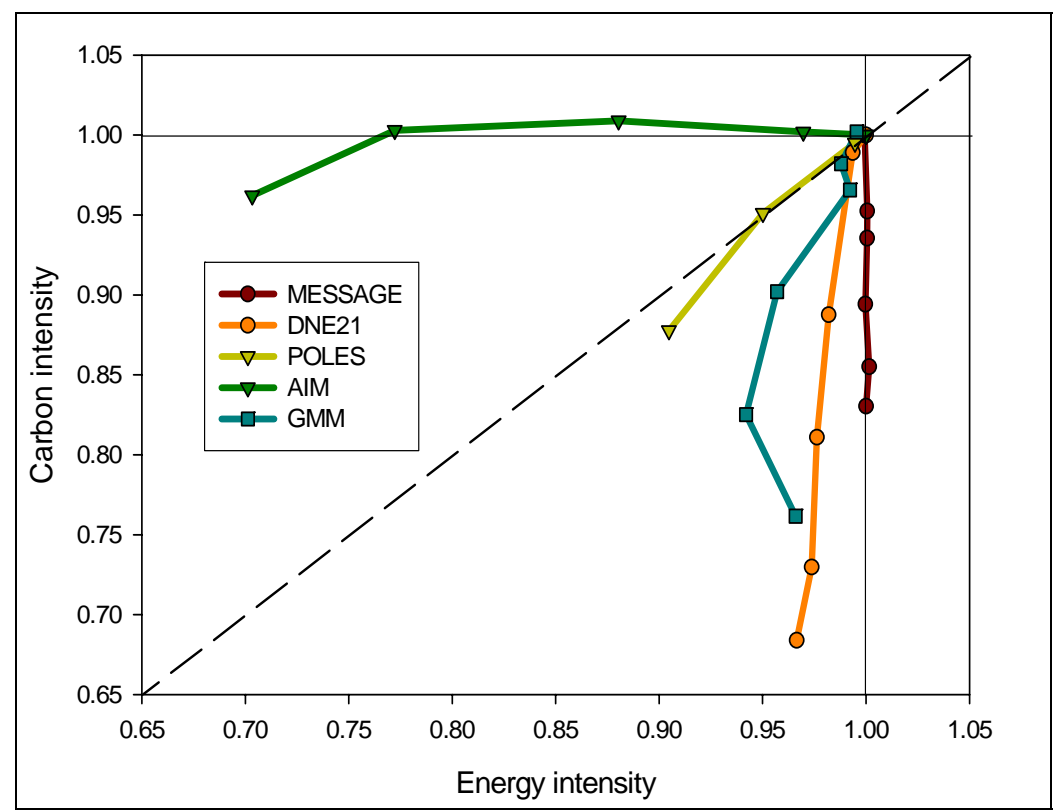

Figure 10: Relative change of Carbon intensity for the Soft-Landing case

These results seem to suggest that policies that encourage fuel switching to less carbon intensive fuels may be of higher importance than those aiming at improving energy efficiency. But a great care is required in the interpretation of these results, since in most of the world models used demand side technologies are not treated with as much detail as supply side technologies ${ }^{25}$.

\section{Main result of the model comparison}

While flexibility mechanisms may be an efficient approach to GHG reductions, the price of permits is still subject to a high degree of uncertainty. Even with the same basic assumptions the permit price indeed shows significant variations across models. A fundamental reason for this is the fact that different assumptions or results on the future energy demand level and structure lead to significant differences in the baselines and corresponding emission levels. Indeed for comparable reduction levels the models show very similar carbon values, indicating a similar global sensitivity to the introduction of a price signal.

\section{CONCLUSIONS}

The purpose of this paper was to illustrate how an active policy to reduce $\mathrm{CO}_{2}$ emissions may affect the energy system and which permit prices would be associated with such a policy in an assumed emission permit market.

To this end the "soft landing" scenario has first been defined. It has been shown that emission targets as set in this scenario would achieve significant environmental targets, while taking into account the constraints of developing countries and international equity concerns.

\footnotetext{
${ }^{25}$ Since most of the models are partial equilibrium models structural changes caused by emission reduction cannot be captured. A more detailed analysis on sectoral impacts of the soft landing scenario can be found in Mantzos et al., 2004 presenting results of the GEM-E3 model..
} 
The target defined in the scenario asks for a reduction in emissions of about $20 \%$ (from the POLES baseline) and consequently the impact on the world energy system is significant. However, the results of the POLES model show that with this level of reduction the structure of the energy system will not change dramatically at least until 2030. Even if nuclear and renewable energy show considerable increases in their contributions by this date, the bulk of electricity will still be generated using fossil fuels. Indeed a considerable part of the emission reduction in the power sector is achieved by fuel switching from coal to natural gas: while in the baseline without emission restriction advanced coal technologies contribute to a major extent to the development in electricity generation, in the soft landing case a large part of the corresponding new plants will be replaced soft landing by gas based technology.

The allowed emission trading provides the necessary degree of flexibility in the emission reduction effort so that the target can be met without having to fully restructure the energy system and thus without excessive cost. The analysis of this scenario demonstrates that, assuming international trading, the effort to meet the constrained emission profile is increasing smoothly over time and hence the scenario indeed corresponds to a "soft landing" for world $\mathrm{CO}_{2}$ emissions.

In 2030 the world regions are almost clearly divided in industrialised countries and regions that buy permits and developing countries that sell permits. Japan and Canada cover almost half of their emission reduction obligations by purchasing permits. The EU27 achieves two third of the emission reduction obligations domestically. The important selling nations are India, the former Soviet Union and - the largest of all China, that contributes close to one third of the permits traded in 2030. The assumption that the USA will start reduction only after 2010 from the emission level reached by then produces an exception with the USA being the only high income region that is exporting emission permits. This hypothesis may have to be re-examined in further works, also taking into account developments in international negotiation.

The inter-model comparison as carried out within the ACROPOLIS project shows that the answers of the various models as to how to meet emission targets vary to a considerable extent. Even with harmonised basic exogenous assumptions, the projected emissions in the baseline without $\mathrm{CO}_{2}$ emission reduction obligations differ noticeably. This translates into different reduction efforts to meet the common emission targets across models and explains differences in the computed permit prices in the assumed emission permit market. Also the balance of energy intensity and carbon intensity effect seem quite different from one model to another. However, when the differences in the emission reduction effort from baseline is accounted for, then the permit prices show a higher degree of convergence across the different for the models.

\section{Acknowledgment}

We would like to thank Silvana Mima and Alban Kitous (LEPII-EPE ) as well as Laszlo Szabó (IPTS) for their contributions to the work described in this article. A major part of the research presented in this paper has been funded within the ACROPOLIS project of the European Commission (see introductory article of this Special Issue). 


\section{References}

Banuri, T., Göran-Mäler, K., Grubb, M., Jakobson, H.K.., Yamin F., 1996. Equity and Social Considerations, in: J.P. Bruce, L. Hoesung, E.F. Haites (eds.), Climate Change 1995. Contribution of Working Group III to the Second Assessment Report of the Intergovernmental Panel on Climate Change, pp. 83-124.

Blanchard, O., Criqui, P., Trommetter, M., Viguier, L., 2000. Au-delà de Kyoto: Enjeux d'équité et d'efficacité dans la négociation sur le changement climatique. Economie et Prévision 143-44 (2-3): 15-35.

Blanchard, O., Criqui, P., Trommetter, M., Viguier, L., 2001. Equity and efficiency in climate change negotiations: a scenario for world emission entitlements by 2030. Grenoble, IEPE, Cahier de Recherche $n^{\circ} 26$.

Böhringer, C., 2001. Climate Politics from Kyoto to Bonn: from little to Nothing, Discussion Paper No. 01-49. Zentrum für Europäische Wirtschaftsforschung, Mannheim.

Criqui, P., Mima, S., Viguier, L., 1999. Marginal abatement costs of $\mathrm{CO}_{2}$ emission reductions, geographical flexibility and concrete ceilings: an assessment using the POLES model, Energy Policy, October 27, pp. 585-601.

Criqui, P., Russ, P., Debye, D., 2004. Short-term impact of a multi-gas approach in policy scenario analysis and consequent operational implications - The POLES-Gecs modelling system, to be published in Special Issue on EMF-21, Energy Journal.

Das, A. et al., 2004. ACROPOLIS: an Example of International Collaboration in the Field of Energy Modelling to Support Greenhouse Gases Mitigation Policies, in this Special Issue of Energy Policy.

ENERDATA , 2004. World Energy Database, Gieres, Grenoble, France.

Energy Journal, Special issue, 1999. The costs of the Kyoto Protocol: a multi-model evaluation.

European Commission, 1996. POLES 2.2, European Commission DG XII, EUR 17358 EN, 1996

European Commission, 2003a. World Energy, Technology and Climate Policy Outlook 2030 (WETO). European Commission, DG RTD, EUR 20366 EN, 2003.

European Commission, 2003b. Greenhouse gas reduction pathways - In the UNFCC process up to 2025, Report for the European Commission DG ENV, http://europa.eu.int/comm/environment/climat/pdf/pm_techreport2025.pdf

European Council, 1996. 1939 ${ }^{\text {th }}$ Council meeting (ENVIRONMENT), Luxembourg, 25 June 1996, Community strategy on climate change - Council conclusions, paragraph 6.

Gusbin, D., Klaassen, G., Kouvaritakis, N., 1999. Costs of Ceiling on Kyoto Flexibility. Energy Policy, 27(1999) 833-844 
IPCC (Intergovernmental Panel on Climate Change), 1996. Climate Change 1995 Economic and social dimensions of climate change, Contribution of Working Group III to the Second Assessment Report of the Intergovernmental Panel on Climate Change, Cambridge University Press, Cambridge.

IPCC (Intergovernmental Panel on Climate Change), 2001. Climate Change 2001:Mitigation. Contribution of Working Group III to the Third Assessment Report of the Intergovernmental Panel on Climate Change. Cambridge: Cambridge University Press.

Mantzos, L., Paroussos, L., Zeka-Paschou M., 2004. Energy and economic consequences of flexibility in meeting climate change constraints, in this Special Issue of Energy Policy.

Rose, A., Stevens B., Edmonds J., Wise M., 1998. International Equity and Differentiation in Global Warming Policy, Environmental and Resource Economics, 12, pp 25-51.

Russ, P., 2004. The role of accelerated power generation technology development to reduce carbon dioxide emissions. To be published in Energy \& Environment, 2004.

UNCTAD (United Nations Conference on Trade and Development). 2001.Greenhouse Gas Market Perspectives: Trade and Investment Implications of the Climate Change Regime. UNCTAD/DIT/TED/Misc.9. New York and Geneva.

UNFCCC (United Nations Framework Convention on Climate Change), 1992. New York, May 9. United Nations Framework Convention on Climate Change (UNFCCC), Ad Hoc Group on the Berlin Mandate (1996), Strengthening the commitments in article 4.2 (A) and (B): quantified emissions limitation and reduction objectives within specified timeframes: review of possible indicators to define criteria for differentiation among Annex I Parties, Note by the Secretariat, FCCC/AGBM/1996/7, 21 June.

UNFCCC (United Nations Framework Convention on Climate Change, 1997. Kyoto Protocol to the United Nations Framework Convention on Climate Change.

Wigley, T.M.L., Richels R., Edmonds, J.A., 1996. Economic and Environmental Choices in the Stabilisation of Atmospheric $\mathrm{CO}_{2}$ Concentrations; Nature 379(6562):240-243.

Wigley, T.M.L., Raper, S.C.B., Hulme, M., Smith, S., 2000. The MAGICC/SCENGEN Climate Scenario Generator: Version 2.4, Technical Manual, Climatic Research Unit, UEA, Norwich, UK. 


\section{Annex: The POLES model - An Overview}

POLES (European Commission, 1996) is a global sectoral simulation model for the development of long-term (2030) energy supply and demand scenarios. For global energy scenarios (European Commission, 2003a), the model provides endogenous international energy prices and all information on energy flows for each country / region. A major part of recent applications has been dedicated to studies assessing greenhouse gas abatement policies (see eg. Gusbin et al., 1999, European Commission, 2003b).

The POLES (Prospective Outlook for the Long-term Energy System) model has been developed in the framework of a hierarchical structure of interconnected sub-models at the international, regional, national level. The dynamics of the model is based on a recursive (year by year) simulation process of energy demand and supply with lagged adjustments to prices and a feedback loop through international energy prices.

In the POLES 5 version of the model, the world is divided into thirty eight countries or regions, allowing to identify the key world regions of most energy studies: North America; South America; Western Europe; Central Europe; Former Soviet Union; North Africa and Middle-East; Africa South of Sahara; South Asia; South East Asia; Continental Asia; Pacific OECD.

For each region, the POLES model articulates four main modules dealing with:

- Final energy demand by main sector,

- New and renewable energy technologies,

- The conventional energy and electricity transformation system,

- $\quad$ Fossil fuel supply.

While the simulation of the different energy balances allows for the calculation of import demand / export capacities by region, the horizontal integration is ensured in the energy markets module, the main inputs of which are import demand and export capacities of the different regions. Only one world market is considered for the oil market (the "one great pool" concept), while three regional markets (America, Europe, Asia) are identified for coal, in order to take into account for different cost, market and technical structures. Natural gas production and trade flows are modelled on a bilateral trade basis, thus allowing for the identification of a large number of geographical specificities and the nature of different export routes. 